\title{
Floral traits and pollination system of Zygophyllum xanthoxylum in the managed and wild populations in an arid region of Northwest China
}

\author{
CHEN Min ${ }^{1,2^{*}}$, ZHAO Xueyong ${ }^{1}$, ZUO Xiao'an $^{1}$, LIAN Jie $^{1}$, ZHU Yangchun ${ }^{1,2}$ \\ ${ }^{1}$ Cold and Arid Regions Environmental and Engineering Research Institute, Chinese Academy of Sciences, Lanzhou 730000, China; \\ ${ }^{2}$ University of Chinese Academy of Sciences, Beijing 100049, China
}

\begin{abstract}
Zygophyllum xanthoxylum, which belongs to Sarcozygium of Zygophyllaceae, is one of the ecologically important species in Northwest China. In order to understand the pollination system of $Z$. xanthoxylum, we investigated the following characteristics of this species in the Urat Desert-grassland Research Station in western Inner Mongolia of China: flowering dynamics, pollen viability, pollen limitation, floral visitors and breeding system. The results showed that the flowering period and flowering peak were different between the wild and managed populations, being longer in the managed population. Z. xanthoxylum was pollen-limited, and pollen limitation was more intense in the wild population than in the managed population. Chalicodoma deserticola (Hymenoptera) was found to be the most frequent pollinator in the wild population, while Anthophora fulvitarsis (Hymenoptera) was the most frequent and effective visitor in the managed population. Out-crossing was dominant in the breeding system and self-pollination just played an assistant role to assure the reproduction of $Z$. xanthoxylum.
\end{abstract}

Keywords: Zygophyllum xanthoxylum; pollination; pollen limitation; floral visitor; fruit set; seed set; breeding system

Citation: CHEN Min, ZHAO Xueyong, ZUO Xiao'an, LIAN Jie, ZHU Yangchun. 2015. Floral traits and pollination system of Zygophyllum xanthoxylum in the managed and wild populations in an arid region of Northwest China. Journal of Arid Land, 7(4): 488-500. doi: $10.1007 / \mathrm{s} 40333-015-0042-\mathrm{z}$

Pollination is a key process in terrestrial communities, being the first stage in sexual reproduction of plants, and an essential prerequisite for the development of fruits and seeds (Kevan et al., 1990). Therefore, pollination affects the variety of ecological and evolutional processes of many plant species, such as floral attraction, plant mating system and population persistence (Bond, 1994; Kearns et al., 1998; Ashman et al., 2004; Ashman and Morgan, 2004). Pollination traits have an important influence on the growth, development and reproduction of plants. Like other living things, plants can't be separated from environmental factors and exist alone. On the one hand, the temperature, moisture, air, animal, soil and other factors play important ecological roles in the growth and development of plants. On the other hand, plants have adaptability and different responses to the changes of environmental factors through pollination traits. Studying pollination traits is helpful to understand the reproductive success of plants, as well as environmental factors influencing the dynamics of populations (Arias-Cóyotl et al., 2006).

For flowering plants, successful pollination is a prerequisite for sexual reproduction. However, plants under natural pollination conditions often suffer from pollen limitation (Ashman et al., 2004; Knight et al., 2006). For example, the small populations only could attract fewer pollinators, resulting in the reduced stigma pollen load and decreased fruit set. Pollen limitation happens when plant reproduction is limited by the quantity or quality of pollen-received, meanwhile pollinators are low in abundance or pollinator services are unreliable in environments (Byers, 1995; Ashman et al., 2004; Aizen and Harder, 2007). In arid environments, pollinator service is more unreliable and persistently

\footnotetext{
"Corresponding author: CHEN Min (E-mail: chenmin1360@126.com) Received 2014-09-11; revised 2014-11-20; accepted 2014-12-09

(C) Xinjiang Institute of Ecology and Geography, Chinese Academy of Sciences, Science Press and Springer-Verlag Berlin Heidelberg 2015
} 
low. Xerophilous plants that depend on pollinator services are most likely to be pollen-limited because insect pollinators are lower in diversity and abundance in arid regions. Additionally, the climate in arid habitats is typically windy, curtailing flying insect foraging time. Sexual selection theory once optimistically predicted that plant reproduction should not be limited by pollen receive (Janzen, 1977; Wilson et al., 1994). However, recent studies indicated that pollen limitation is widespread in plants (Burd, 1994; Larson and Barrett, 2000; Knight et al., 2006). The potential consequences of pollen limitation for plant populations have been extensively studied over the last decades (Burd, 1994; Larson and Barrett, 2000; Knight et al., 2006). To access pollen limitation, most studies have added extra pollen to flowers of some plants and compared the fruit or seed sets from these plants with those from control plants subjected to natural pollination (e.g. Ashman et al., 2004).

The management of vegetation clearance involves artificial selection of targeted morphological types for use. For instance, plant species which can produce more fruits were generally preferred, and this selection has caused changes in phenotype frequencies between the wild and managed populations (Casas et al., 2007). Likewise, some studies have documented differences in reproductive traits between the wild and managed plant populations, which indicated that vegetation clearance and hand pollination caused the processes of domestication (Brenda et al., 2006; Ortíz et al., 2010).

Zygophyllum xanthoxylum is an ecologically important species and widely distributed in arid regions of Northwest China. It plays an important role in arid environments because its root system is very efficient in absorbing water, making it resists drought and salt. Z. xanthoxylum often forms stable community, and its community has significant role in sand fixation and has high vegetation productivity. Its flowers and roots can be used as medicine ( $\mathrm{Li}$ and Teng, 1990). However, Z. xanthoxylum community was severely degraded due to drought and over-grazing in the past 30 years (Liu, 1987). So, Z. xanthoxylum needs to be protected in China.

Recent studies on Z. xanthoxylum were mainly focused on its geographical distribution, biological characteristics, physiological stress and molecular biology (Wu et al., 2011a, b; Hu et al., 2012; Ma et al., 2012; Yue et al., 2012; Li et al., 2013). Based on the understanding of the above researches and practical concern, as well as the lack of studies on pollination, pollen limitation and breeding system of $Z$. xanthoxylum, we raised three theoretical questions and one practical question. The theoretical question is what are the differences of pollination and the limitation factors between the wild and managed populations of Z. xanthoxylum, and which environmental factors plays a main role in the pollination process. The practical question is that is it possible to protect the degraded $Z$. xanthoxylum population and/or community to be restored by manipulation to pollination process. This study thus aimed to compare the pollination traits of $Z$. xanthoxylum in the wild and managed populations through testing the management influence on flower production and pollen limitation intensity in the two populations, the floral visitor and activity in-between the two populations, and the co-effect of out-crossing and self-pollination.

\section{Materials and methods}

\subsection{Study area and plant species}

The investigation was carried out in the Urat Desert-grassland Research Station in western Inner Mongolia of China $\left(41^{\circ} 06^{\prime}-41^{\circ} 25^{\prime} \mathrm{N}, 106^{\circ} 59^{\prime}-107^{\circ} 05^{\prime} \mathrm{E}\right.$; 1,020-1,050 m asl; Fig. 1). From 2013 to 2014, the annual precipitation is about $96.0-105.9 \mathrm{~mm}$, and the annual average temperature is $3.8^{\circ} \mathrm{C}$ with the extreme maximum of $36^{\circ} \mathrm{C}$ and the extreme minimum of $-29^{\circ} \mathrm{C}$ in the study area.

Z. xanthoxylum, a drought-resistant shrub with about $90-\mathrm{cm}$ height, is mainly distributed in western Inner Mongolia, northwestern Ningxia and western Gansu. It is one of the dominant species in the study region. The leaf of $Z$. xanthoxylum is linear with the lengths of 8-24 mm. Z. xanthoxylum has yellowish bisexual flowers with four petals and eight stamens. The stigma is usually of two splits (Fig. 2).

In this study, we selected the wild population of $Z$. xanthoxylum in the region where its flowering time does not overlap with other plant species. Three plots were set up (each plot had an area of $150 \mathrm{~m}^{2}$ ) and separated by $300-500 \mathrm{~m}$ away from each other in this 

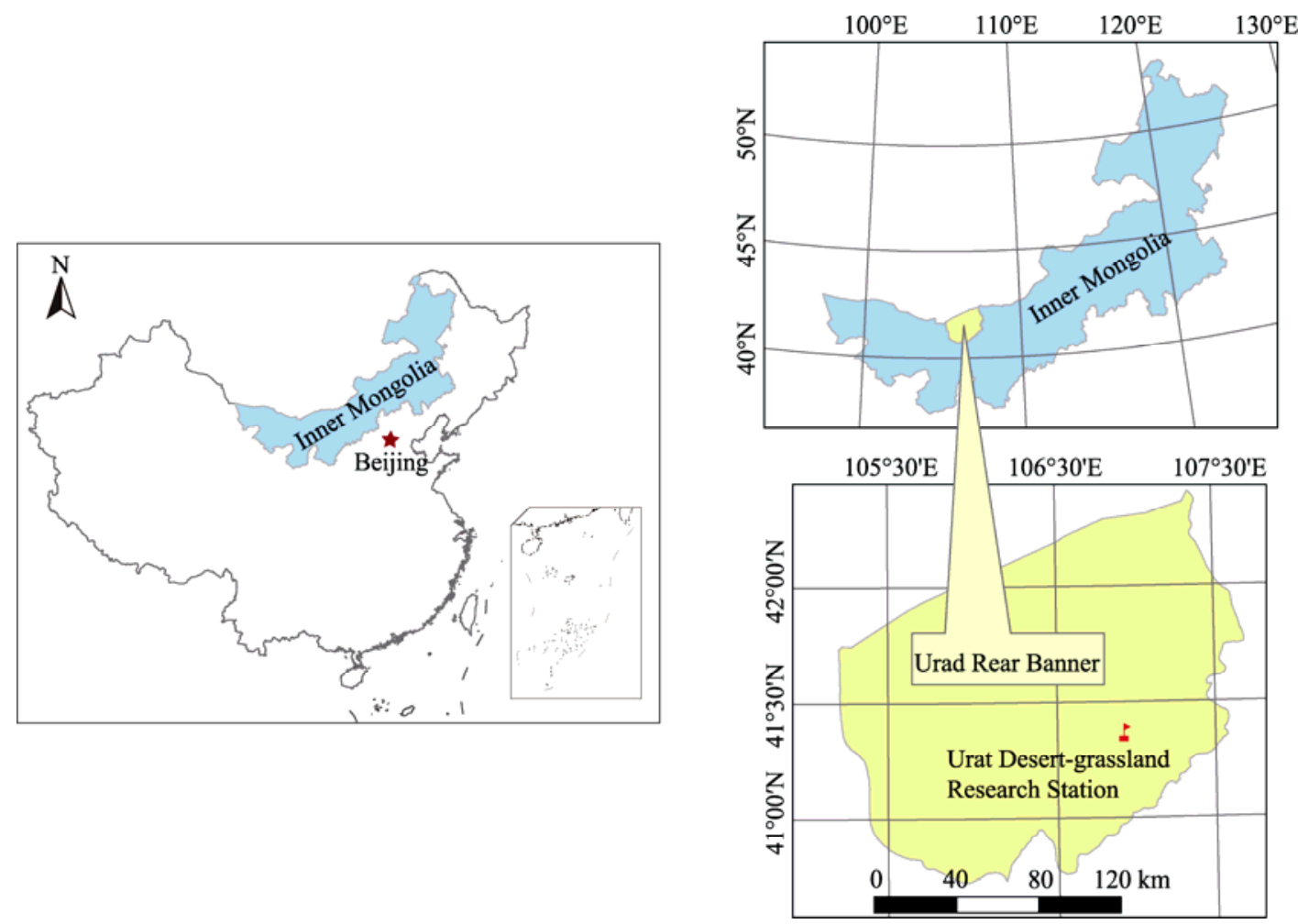

Fig. 1 The location of the study area in Inner Mongolia autonomous region, China

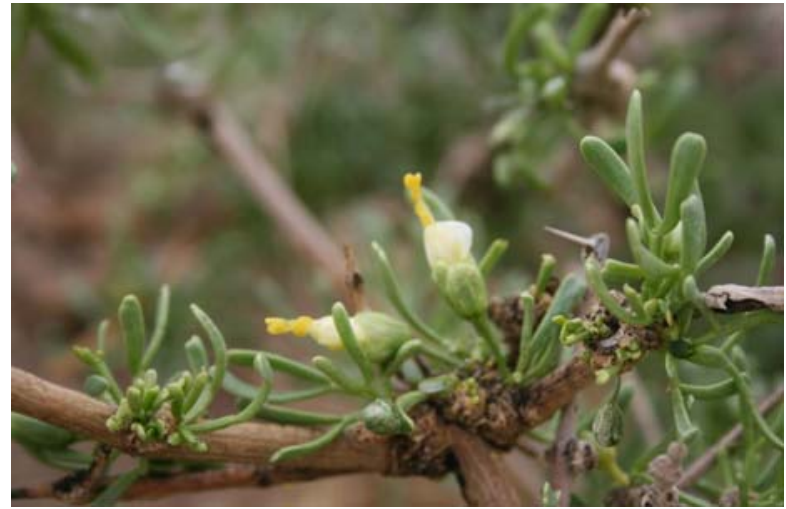

Fig. 2 Flower of Zygophyllum xanthoxylum in the flowering period of the study area

region. The average density of $Z$. xanthoxylum was 10 individuals per $100 \mathrm{~m}^{2}$. The managed population of $Z$. xanthoxylum was nearly $6 \mathrm{~km}$ away from the wild population and the two habits possessed the similar landform and plant communities. This is to avoid mutual interference of different pollinators in different populations. In the managed population, other plant species (e.g. Caragana microphylla and Reaumuria songarica) but $Z$. xanthoxylum were repeatedly cleared. Three plots were set up in the interval of
100-300 m, and each plot had an area of $150 \mathrm{~m}^{2}$. The average density of $Z$. xanthoxylum was 16 individuals per $100 \mathrm{~m}^{2}$. All the studied plots were managed by the local researchers.

\subsection{Phenological observation}

The phenological characters of Z. xanthoxylum were observed following the method of Ortíz et al. (2010). A total of 40 plants (20 from the wild population and 20 from the managed population) were selected to observe the phenological process of this species. For each individual plant, the flower buds, flowers in anthesis and fruits of each branch were counted at an interval of 6 days in the entire reproductive season (April 2012 to October 2013). The total number of flower buds, flowers in anthesis and mature fruits were recorded.

\subsection{Floral trait}

The targeted shrubs were observed every day and the changes of flowering period and anther dehiscence were recorded following the methods of Spira et al. (1992) and Kudo (1993). Measurements also included the flower length (from petal tip to flower base), ex- 
ternal diameter of the corolla apex and stamen, and flower diameter. Video filming was conducted continually throughout anthesis in 3-5 flowers from two individual plants per population. The timing of the following events was recorded, i.e. anthesis begins, flowers completely open, pollen release, flower closing starts and flowers completely close. These observations were supplemented with more precise continuous filming of anthesis.

\subsection{Pollen viability}

Pollen viability was measured using the in vitro germination method (Chen, 2009). Pollen grains isolated from flowers were immediately incubated in a culture medium containing $5 \%(\mathrm{w} / \mathrm{v})$ sucrose, $0.01 \%$ (w/v) $\mathrm{CaCl}_{2}, 0.01 \%(\mathrm{w} / \mathrm{v}) \mathrm{H}_{3} \mathrm{BO}_{3}$ and $0.01 \%(\mathrm{w} / \mathrm{v})$ $\mathrm{KH}_{2} \mathrm{PO}_{4}$ at $30^{\circ} \mathrm{C}(\mathrm{pH} 7.0)$. The pollen grains were counted for a 24 -h period using a stereozoom microscope. These pollen grains were considered as germinated when the length of the pollen tubes was longer than the diameter of the pollen grain. For each glass slide, five fields were analyzed and 100 pollen grains were counted.

\subsection{Pollen limitation}

Pollen limitation was examined according to the method of Ashman et al. (2004). Ashman et al. (2004) examined the effects of pollen limitation at the whole plant level but did not include the potentially confounded effects of resource reallocation. In this study, we used two complementary controls (one from manipulated plants and the other from non-manipulated ones) as the procedural control. We set up three pollination treatments to estimate the relative impact of wind and insect pollination on fruit set. The three treatments were control $(\mathrm{C})$, procedural control $(\mathrm{CC})$ and pollen added (PA).

We also conducted a pollen-supplementation experiment in six focal plots to estimate pollen limitation. In each plot, we randomly labelled twelve healthy plants at the same flowering stage. One inflorescence was sampled from all targeted plants with similar size. Eight flowers were labelled from the central part of the flowering stalk of eight randomly labelled plants, adding outcross pollen in the upper four flowers as the PA treatment and leaving the lower four flowers as the $\mathrm{C}$ treatment. Four flowers were also labelled from the central part of the remained four plants and regarded as the $\mathrm{CC}$ treatment. Finally, a total of 576 flowers (six plots, twelve plants per plot, one inflorescence per plant, eight flowers in each inflorescence) were tagged. All the flowers were freely exposed to insect pollinators after they had been opened manually.

Flowers in PA and C treatments were chosen from the same part of the stalks to avoid the effects of flower position on reproduction and pollen limitation (Casper and Niesenbaum, 1993; Wesselingh, 2007; Gómez et al., 2010). We randomly selected four flowers in PA treatment and four flowers in C treatment and applied the treatments in the inflorescence. Flowers in $\mathrm{CC}$ treatment were used to detect the possible effects of pollen supplementation on re-allocation of resources from flowers in $\mathrm{C}$ treatment (Wesselingh, 2007; Gómez et al., 2010). The PA treatment was carried out when the flowers were opened and the plants were hand-pollinated by saturating the stigma with fresh pollen obtained from another plant which was at least $15 \mathrm{~m}$ away. The newly receptive flowers were pollinated from 07:00-19:00 for seven days. By the end of the reproductive season, we counted the number of experimental flowers that had produced fruits.

In this study, we used the proportion of flowers setting fruit to estimate the pollen limitation. The pollen limitation indices for $\mathrm{C}$ and $\mathrm{CC}$ treatments were calculated according to Eq. 1 and Eq. 2, respectively (Larson and Barrett, 2010).

$$
\begin{aligned}
\mathrm{PL}_{\mathrm{C}} & =1-\left(\mathrm{RS}_{\mathrm{C}} / \mathrm{RS}_{\mathrm{PA}}\right), \\
\mathrm{PL}_{\mathrm{CC}} & =1-\left(\mathrm{RS}_{\mathrm{CC}} / \mathrm{RS}_{\mathrm{PA}}\right) .
\end{aligned}
$$

Where, $\mathrm{PL}_{\mathrm{C}}$ is the pollen limitation under $\mathrm{C}$ treatment, $\mathrm{PL}_{\mathrm{CC}}$ is the pollen limitation under $\mathrm{CC}$ treatment, $\mathrm{RS}_{\mathrm{C}}$ is the fruit set under $\mathrm{C}$ treatment, $\mathrm{RS}_{\mathrm{PA}}$ is the fruit set under PA treatment, and $\mathrm{RS}_{\mathrm{CC}}$ is the fruit set under $\mathrm{CC}$ treatment. The value of pollen limitation index ranges from 0 to 1 , and 0 means no pollen limitation and 1 means the highest pollen limitation (Larson and Barrett, 2000).

\subsection{Flower visitors}

In the field, pollination process was observed and recorded, and pollinators were captured with hand net, which whether any pollen grains were attached to their bodies was determined. There were a total of $15 \mathrm{ob}-$ 
servation periods from April to May, and each period was eight days from 07:00 to 19:00. Visitors were tracked visually for as long as possible until they left the focal population, and their foraging sequence within and between plants was recorded during each observation period. A pollinator foraging in one flower was considered as one visit. Pollen was collected by using a cube of fuchsin-stained jelly to rub the insect body following the Beattie's method (Beattie, 1971). Visitation frequency of insects to flowers and the foraging time for different insects were observed every hour.

\subsection{Breeding system}

The breeding system of Z. xanthoxylum was studied by controlling crossings on flowers bagged in the pre-anthesis. A total of six treatments were designed before flower opening: (1) control, inflorescences with floral buds were marked at random and maintained under natural conditions (i.e. flowers free to visitors; Dafni, 1992); (2) manual cross-pollination, pollen from 20 individual plants was collected and used to pollinate flowers of other individual plants whose stamens were previously removed; (3) non-manipulated self-pollination, flowers were covered with exclusion bags and maintained in this condition until fruits maturing; (4) manual self-pollination, flowers were pollinated with their own pollen and then re-bagged; (5) emasculated and netting, emasculation was performed before the flowers opened and nylon nets with $1-\mathrm{mm}^{2}$ mesh size were used to cover flowers and prevent insects from visiting the flowers; and (6) emasculated without bags. The ideal sample designed for each treatment was 60 flowers. However, some treatments have different sample sizes due to limitations in the field (e.g. loss of treated flowers by rain or herbivores). The experiment was conducted in early May. Except the control group, the emasculated and netting group, and the emasculated without bags group, all sample flowers in the other three treatments were covered with exclusion bags. After the treatments of non-manipulated self-pollination, manual cross-pollination and self-pollination were applied, flowers from the three groups were covered again with exclusion bags. In September, all seeds harvested from the bagging ex- periments were put into subsequent germination tests in the laboratory.

The self-compatibility index (SCI) was also calculated. SCI was calculated by the average seed set of manual self-pollination divided by the average seed set of manual cross-pollination (Zapata and Arroyo, 1978; Lloyd and Schoen, 1992). SCI value $\leq 0.2$ indicates self-incompatibility, whereas the value $>0.2$ indicates self-compatibility (Zapata and Arroyo, 1978; Lloyd and Schoen, 1992).

\subsection{Statistical analysis}

The data were transformed using the arcsine squareroot function for the whole sample of 40 plants for comparing the production of reproductive structures (i.e. flower buds, flowers in anthesis and mature fruits) between the two populations. We used the generalized linear models (Ortíz et al., 2010) with plant as the repeat factor to determine whether habitat condition affects flower buds, flowers in anthesis and fruit production. In this model, the habitat condition, date and the interaction between the habitat condition and date were used as the categorical independent variables.

To compare fruit set between the treatments of PA and $\mathrm{C}, \mathrm{PA}$ and $\mathrm{CC}$, and $\mathrm{C}$ and $\mathrm{CC}$, we performed repeated-measures using treatment as the within subject factor. The quantitative floral characters were compared using one-way ANOVA. The Chi-square test was used to compare seed set between the three pollination treatments. All analyses were performed using the statistical software package SPSS 18.0 for Windows (SPSS Inc., Chicago, IL, USA).

\section{Results}

\subsection{Phenological process of Z. xanthoxylum}

The reproductive season of $Z$. xanthoxylum started in early April and ended in late August. Flower buds were produced throughout the reproductive season, especially abundant in the last week of April.

Significant differences of flowers in anthesis between the wild population and the managed population were identified in the first week of May $(d f=10$, $F=273.6, P<0.05$ ), and many more flowers were recorded in the managed population (Fig. 3). In the populations studied, the first flower was observed in April and the last one by the end of June. The flower pro- 
duction period and flowering peak were different between the wild and managed populations (Fig. 3).

Fruiting started from the first week of May and ended by the end of September (Fig. 4). The fruit production reached the peak at the second week of August in the wild population, while it reached the peak at the end of July in the managed population The fruit production patterns were significantly different between the wild and managed populations $(d f=8, F=153.1, P<0.05)$.

\subsection{Changes of floral trait and pollen viability}

In this study, the flowering times of individuals of $Z$. xanthoxylum from April to October 2012 and 2013 were recorded. In the managed population, the flowers began to open around 07:00 and opened completely about 11:00 (Table 1). The flowering time of each flower lasted a single day. The flower began to close about 13:30 and was completely closed at 19:00. Flowers in the wild population began to open around 07:30 and started to close about 12:00 (Table 1). The number of flowers produced per individual per day was similar in both populations, but the average density of flowers for each individual plant in the managed population $(32.7 \pm 2.9)$ was significantly higher than that in the wild population $(21.6 \pm 1.8 ; d f=1$, $P<0.05$ ). Consequently, the total flowers produced per day in the managed population was significantly higher than that in the wild population $(d f=1, P<0.05)$.

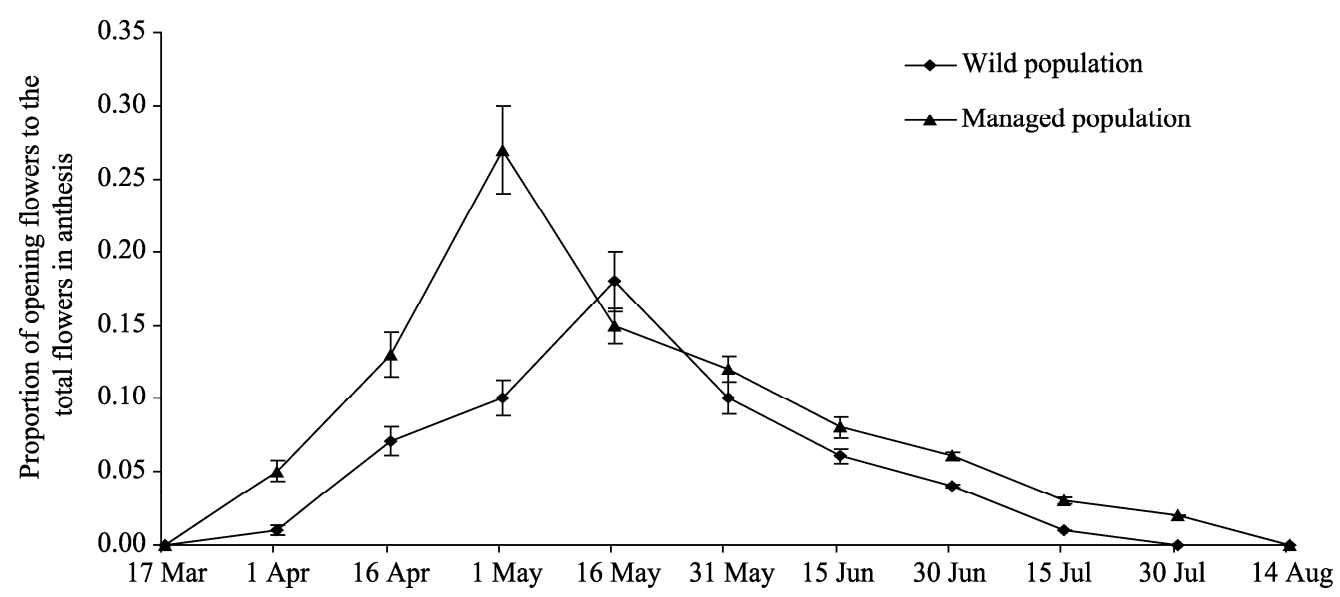

Fig. 3 Proportion of opening flowers to the total flowers in anthesis of the wild and managed populations of $Z$. xanthoxylum. Bars indicate mean $\pm S E$ of flower in anthesis per individual of $Z$. xanthoxylum throughout the reproductive season in the plots ( $n=20$ plants/plot).

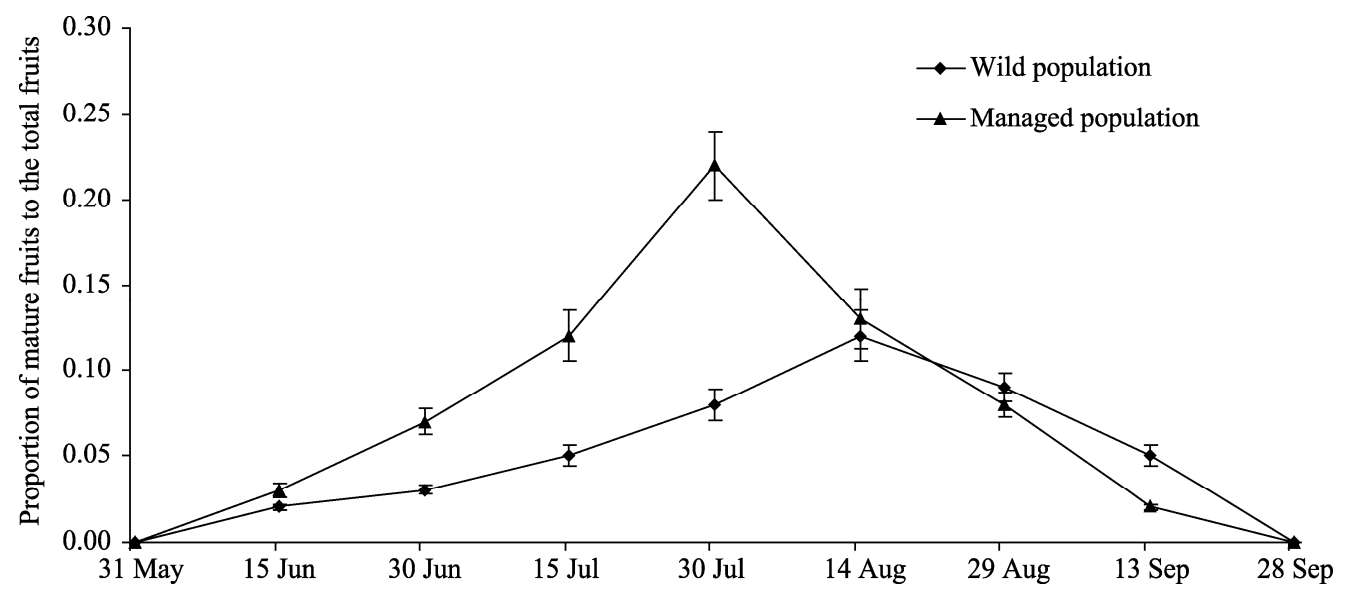

Fig. 4 Proportion of mature fruits to the total fruits in the wild and managed populations of $Z$. xanthoxylum. Bars indicate mean $\pm S E$ of mature fruit per individual of $Z$. xanthoxylum throughout the reproductive season in the plots ( $n=20$ plants/plot). 
Table 1 Timing of flower anthesis in the wild and managed populations of Zygophyllum xanthoxylum

\begin{tabular}{lcc}
\hline \multirow{2}{*}{ Event } & \multicolumn{2}{c}{ Time } \\
\cline { 2 - 3 } & Wild population & Managed population \\
\hline Anthesis begins & $07: 30-08: 00$ & $07: 00-08: 30$ \\
Flowers completely open & $08: 30-10: 00$ & $08: 30-11: 00$ \\
Pollen release & $08: 00-14: 00$ & $08: 00-15: 00$ \\
Flower closing starts & $12: 00-13: 00$ & $13: 30-14: 00$ \\
Flowers completely close & $18: 00-18: 30$ & $18: 30-19: 00$ \\
\hline
\end{tabular}

The flowering period for each individual flower was four days in the managed population and two to three days in the wild population. The pollen viability was as high as $65.2 \%$ or more in the first flowering day in both populations. It peaked at $83.21 \% \pm 7.27 \%$ (mean \pm SD; $n=20$ flowers) in the managed population and $77.60 \% \pm 6.30 \%$ ( $n=20$ flowers) in the wild population. The stigma was receptive from the beginning of flowering until closed. In non-pollinated flowers, the stigma became dry about 12:30. For the two populations, the length of petals, sepals and stamens was $9.12 \pm 0.86,5.71 \pm 0.61$ and $15.26 \pm 1.2 \mathrm{~mm}($ mean $\pm \mathrm{SD})$, respectively.

\subsection{Pollen limitation}

Pollen limitation was proportionally more intensive in the wild population $(\mathrm{PLc}=0.333 \pm 0.024)$ than in the managed one $(\mathrm{PLc}=0.232 \pm 0.021)$. In the managed population, the fruit set of flowers did not differ significantly between the $\mathrm{C}$ and $\mathrm{CC}$ treatments, with $62.5 \% \pm 5.5 \%$ in $\mathrm{C}$ treatment and $61.2 \% \pm 5.1 \%$ in $\mathrm{CC}$ treatment. The fruit set of flowers in PA treatment was $81.5 \% \pm 6.2 \%$, showing a strong positive pollen limitation (Table 2). In the wild population, the fruit sets of flowers were $49.5 \% \pm 4.3 \%$ in $\mathrm{C}$ treatment, $47.4 \% \pm 3.9 \%$ in $\mathrm{CC}$ treatment and $74.5 \% \pm 4.6 \%$ in PA treatment.

Pollen-supplementation did significantly increase the fruit set $(P<0.05)$, according to the comparison of flowers between the PA and C treatments (Table 2). The results of pollen limitation indices also indicated that pollen limitation in the wild population was more severe than that in the managed population.

\subsection{Flower visitors and foraging time}

Flowers of Z. xanthoxylum were mainly visited by bees (Anthophora fulvitarsis), but Chalicodoma deserticola was also recorded in addition to Eristalis cerealis, Pieris rapae and Anthophora plumipes (Fig. 5). Five insect species were recorded, which were considered effective or occasional pollinators. Pollen was collected by the method of Beattie (1971). Almost all the bees were efficient pollinators because their large and hairy bodies could easily carry and deposit more pollen. These bees collected pollen and nectar, and transported the pollen from one flower to another. Bees also visited more flowers per minute than other

Table 2 Effect of pollination treatments on reproductive output of $Z$. xanthoxylum

\begin{tabular}{|c|c|c|c|c|c|c|}
\hline & \multirow{3}{*}{ Treatment } & & \multicolumn{4}{|c|}{ Fruit set } \\
\hline & & & \multicolumn{2}{|c|}{ Wild population } & \multicolumn{2}{|c|}{ Managed population } \\
\hline & & $d f$ & $F$ & $P$ & $F$ & $P$ \\
\hline \multirow[t]{3}{*}{ PA vs. C } & Treatment $(\mathrm{T})$ & 1 & 497.738 & $P<0.01$ & 398.266 & $P<0.01$ \\
\hline & Plot (P) & 5 & 1.132 & 0.370 & 3.946 & 0.009 \\
\hline & $\mathrm{T} \times \mathrm{P}$ & 5 & 3.785 & 0.011 & 2.586 & 0.052 \\
\hline \multirow[t]{3}{*}{ PA vs. CC } & Treatment (T) & 1 & 402.065 & $P<0.01$ & 308.862 & $P<0.01$ \\
\hline & Plot (P) & 5 & 2.934 & 0.033 & 3.939 & 0.009 \\
\hline & $\mathrm{T} \times \mathrm{P}$ & 5 & 1.585 & 0.202 & 2.273 & 0.079 \\
\hline \multirow[t]{5}{*}{ C vs. CC } & Treatment $(\mathrm{T})$ & 1 & 2.545 & 0.124 & 1.495 & 0.233 \\
\hline & Plot (P) & 5 & 3.773 & 0.012 & 4.283 & 0.006 \\
\hline & $\mathrm{T} \times \mathrm{P}$ & 5 & 1.699 & 0.173 & 1.858 & 0.140 \\
\hline & PLc index & & \multicolumn{2}{|c|}{$0.333 \pm 0.024$} & \multicolumn{2}{|c|}{$0.232 \pm 0.021$} \\
\hline & PLcc index & & \multicolumn{2}{|c|}{$0.364 \pm 0.031$} & \multicolumn{2}{|c|}{$0.251 \pm 0.027$} \\
\hline
\end{tabular}

Note: $\mathrm{PA}$, pollen added; $\mathrm{C}$, control; $\mathrm{CC}$, procedural control. $\mathrm{PL}_{\mathrm{C}}$ is the pollen limitation under $\mathrm{C}$ treatment, and $\mathrm{PL}_{\mathrm{CC}}$ is the pollen limitation under $\mathrm{CC}_{\text {treatment. }}$ 


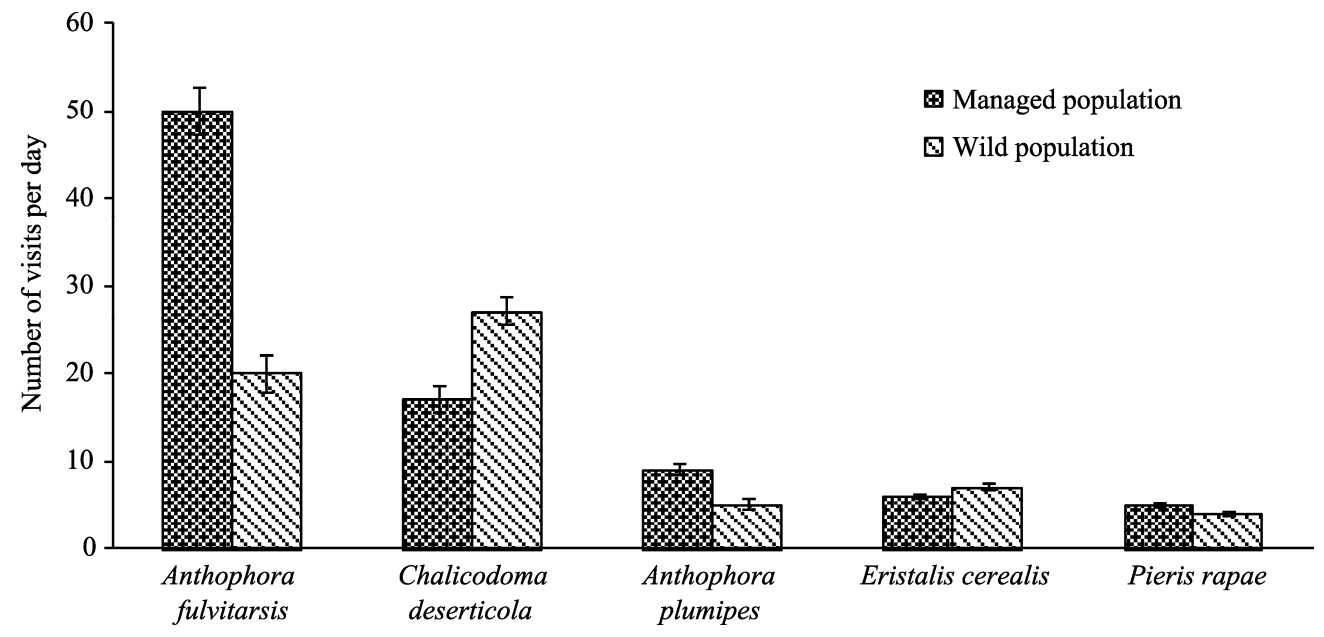

Fig. 5 Average number of insect visits to flowers of $Z$. xanthoxylum in the wild and managed populations. Vertical bars denote standard error.

pollinators. The highest and lowest visitation frequency was $4.82 \pm 0.5$ in the managed population and $2.37 \pm 0.3$ in the wild population, respectively. The differences of visitation frequency in the managed populations were significant higher than those in the wild populations $(P<0.05$; Fig. 6; Table 3$)$.

In the managed population, A. fulvitarsis was the most frequent and effective pollinator because their

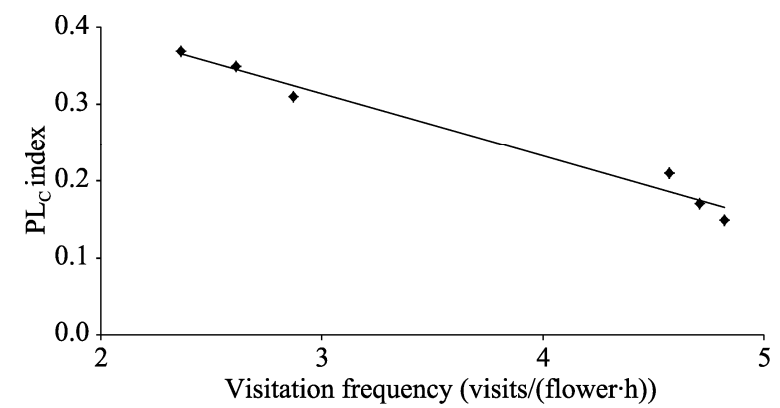

Fig. 6 Relationship between $\mathrm{PL}_{c}$ index per plot and insect visitation frequency. $\mathrm{PL}_{c}$ is the pollen limitation under $\mathrm{C}$ treatment. bodies carried the large amount of pollen grains per visit. This species landed on the stamens with their heads turned toward the flower tube, from which they extracted the pollen with their bodies. They visited almost all of the flowers in anthesis that these pollinators even returned to the same flowers visited previously. The peak of visits was from 10:00 to 16:00 (Fig. 7).

In the wild population, C. deserticola entered the internal flowers through the spaces of tepals without making contact with anthers. The legitimate visit of $C$. deserticola to flowers was only 25 times on average and C. deserticola sometimes contacted both anthers and stigma of flowers. Observed results also showed low visitation frequency in anthers and stigma. Due to little contact with stigmas and the lower pollen load, we considered this insect species was less effective as a pollinator than A. fulvitarsis. C. deserticola played a minor role in the pollination of $Z$. xanthoxylum and the peak of visits was from 11:00 to 14:00. P. rapae

Table 3 Flower number and insect visitation frequency to flowers of $Z$. xanthoxylum and estimates of pollen limitation for fruit set in the wild and managed populations

\begin{tabular}{cccl}
\hline No. & Flower number & Visitation frequency (visits/(flower·h)) & PL $_{\mathrm{C}}$ index \\
\hline Wild population 1 & 17 & $2.61 \pm 0.30^{\mathrm{b}}$ & $0.35 \pm 0.04^{\mathrm{a}}$ \\
Wild population 2 & 20 & $2.36 \pm 0.30^{\mathrm{b}}$ & $0.37 \pm 0.03^{\mathrm{a}}$ \\
Wild population 3 & 19 & $2.87 \pm 0.30^{\mathrm{b}}$ & $0.31 \pm 0.04^{\mathrm{a}}$ \\
Managed population 1 & 23 & $4.71 \pm 0.40^{\mathrm{a}}$ & $0.17 \pm 0.02^{\mathrm{b}}$ \\
Managed population 2 & 20 & $4.82 \pm 0.50^{\mathrm{a}}$ & $0.15 \pm 0.02^{\mathrm{b}}$ \\
Managed population 3 & 22 & $4.57 \pm 0.40^{\mathrm{a}}$ & $0.21 \pm 0.02^{\mathrm{b}}$ \\
\hline
\end{tabular}

Note: Different superscript letters indicate significant differences at $P<0.05$. 


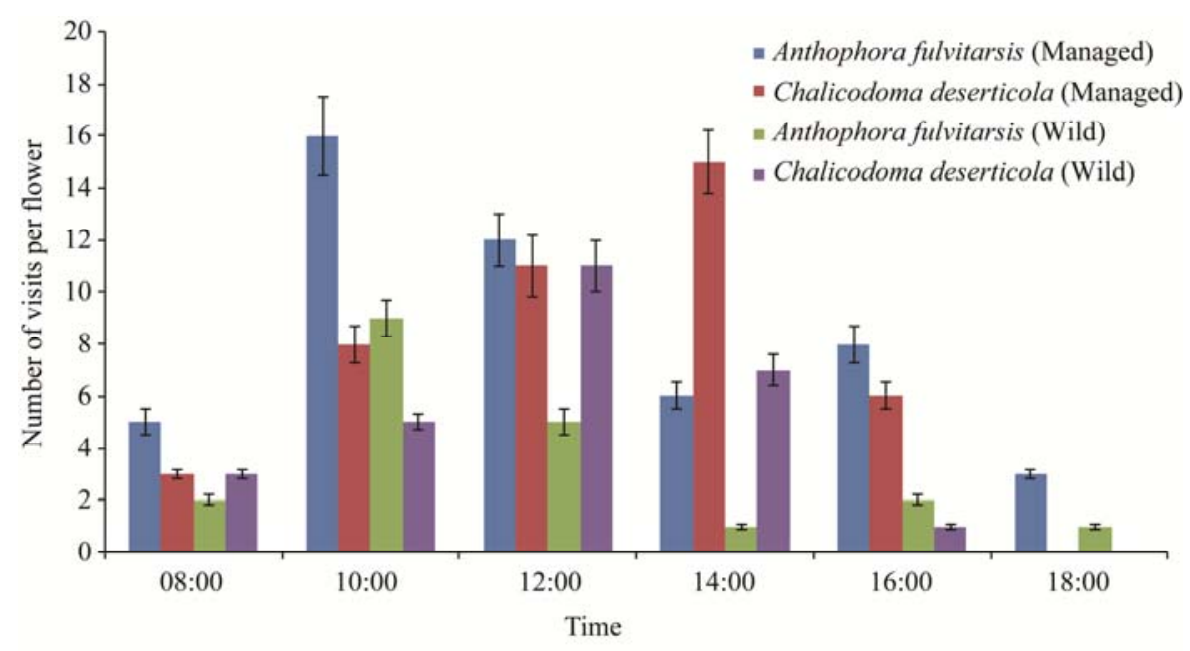

Fig. 7 Frequency of insect visits over time to flowers of $Z$. xanthoxylum in the wild and managed populations. Vertical bars denote standard error.

landed in the lower portion of the corolla and then inserted the proboscis at its opening time. However, due to the position of reproductive structures of the $Z$. xanthoxylum flower, $P$. rapae only has small chance to contact pollen in visits. All of these pollinators showed high foraging in the morning and no bees were observed after 19:00.

\subsection{Breeding system}

Compared to the self-pollination treatment, the seed set was significantly higher in the manual cross-pollination treatment in the two populations (Chi-square test, $P<0.05$; Table 4 ). This indicated that out-crossing successfully promoted the pollination efficiency.

Table 4 Seed set of $Z$. xanthoxylum in the wild and managed populations under different treatments (mean $\pm S D$ )

\begin{tabular}{|c|c|c|}
\hline \multirow{2}{*}{ Treatment } & \multicolumn{2}{|c|}{ Seed set $(\%)$} \\
\hline & Wild population & Managed population \\
\hline Control & $41.9 \pm 3.7$ & $52.6 \pm 4.7$ \\
\hline Manual cross-pollination & $62.7 \pm 5.8$ & $76.5 \pm 6.7$ \\
\hline Non-manipulated self-pollination & $5.7 \pm 0.7$ & $9.8 \pm 1.0$ \\
\hline Manual self-pollination & $15.3 \pm 1.2$ & $23.7 \pm 2.6$ \\
\hline Emasculated and netting & $9.5 \pm 1.1$ & $16.1 \pm 1.2$ \\
\hline Emasculated without bag & $32.1 \pm 3.8$ & $41.5 \pm 4.9$ \\
\hline
\end{tabular}

Under the manual cross-pollination treatment, the seed set was $76.5 \% \pm 6.7 \%$ (5.2 \pm 0.5 seeds per fruit; $n=60$ ) in the managed population and $62.7 \% \pm 5.8 \%$ $(n=60)$ in the wild population. Seed set of the managed population was significantly higher than that of the wild population (Chi-square test, $P<0.05$ ). The seed set of the manual self-pollination samples was $15.3 \%$ in the wild population. The SCI value for $Z$. xanthoxylum was 0.24 , which indicated that this species was self-compatible.

Under natural condition with netting experiment, we found that flowers of both populations only produced a small amount of seeds. However, the flowers were able to produce a lot of seeds in the emasculated treatment under natural condition, and the seeds number in the emasculated treatment was significantly higher than that in the netting treatment (Chi-square test, $P<0.05)$. This indicated that the out-crossing system included insect-pollination and wind-pollination, and the insect-pollination played a more important role in the breeding system.

The self-pollination group had $9.8 \% \pm 1.0 \%(n=60)$ seed set in the managed population and $5.7 \% \pm 0.7 \%$ $(n=60)$ seed set in the wild population. The difference in seed set between the wild and managed populations was significant (Chi-square test, $P<0.05$ ).

\section{Discussion}

Effects of environmental factors on plants are comprehensive. For a specific plant, only one or two factors play a decisive role in the development of plant and this decisive factor is often called the "dominant 
factor". For example, high temperature and drought is the dominant factor for the growth of Cactus in the tropical grassland while air humidity is the main survival-limited factor for the growth of Rhododendron in the low altitude ground. Recent studies found that insect activity is related to the pollination traits (Kawakita, 2010; Camargo et al., 2011; Revel et al., 2012; Wiemer et al., 2012). Global climate change will seriously affect the flowering season and pollinator activity (Saetersdal and Birks, 1997; McCarty, 2001). Insect faunas may be seriously affected by climatic shifts (Kuchlein and Ellis, 1997). Michael et al. (2003) found that some plant species relying on less effective pollinators may experience more serious declines in pollinator services if climate change affects the synchrony of flowering and pollinator activity. Recently, researchers found that the local extinction of pollinators is one threat to rare plant pollination mutualisms (e.g. Spira, 2001).

Because of low pollinator abundance and unreliability of pollinator services in an unfavorable and stochastic climate, plants that rely on pollinator services are considered to be extremely rare in arid habitats. Indeed, our previous data showed low insect visitation rates in the arid areas (Chen et al., 2012; Chen and Zhao, 2014). A high level of reproductive assurance was believed to dominate the plant mating systems of the arid floras and furthermore, was hypothesized to have evolved in response to the limited supply of pollinators (Lloyd, 1980).

Our study indicated that out-crossing was dominant in the breeding system and insect-pollination played an important role in out-crossing. Pollinator behavior has pervasive effects on pollination success or failure. The wild and managed populations were pollinated by pollinators that these species collected and transported pollen, promoting out-crossing. In flower patches, pollinator visitation rates and pollen quality increased with the increases of floral density until a patch becomes saturated with pollinators (Rathcke, 1983). The flower of Z. xanthoxylum is characterized by yellowish corolla and diurnal anthesis. This reproductive structure was related to the enlargement of the visual stimulus to pollinators and accommodated anthers favoring the contact of bees with the stigma. A. fulvitarsis was the most effective pollinator through attaching pollen with their legs and ab- domen. Some pollen was left on the upper part of the stigma when bees moved from one flower to the next. Bees also preferred to visit the managed population than the wild population because the former had the higher density of flower resources. Our results indicated that pollinators were dominant factors for the development of Z. xanthoxylum, and could improve the pollination efficiency by their foraging activities. This was also likely the main cause explaining the different reproductive success between the wild and managed populations.

Flower opening and pollen release of Z. xanthoxylum occurred between 08:30 and 15:00, which was the most crucial time for pollination. This period coincided with the time of most frequent activity of $A$. fulvitarsis and also partially with the activity of $C$. deserticola. When C. deserticola made contact with anthers, only a small amount of pollen was actually removed because of its small size. Impact of the activities of $C$. deserticola on the reproductive success of $Z$. xanthoxylum was not clear because the peak visits of C. deserticola presented in a later period than the peak visits of bees. Similar pattern of pollinator visitation frequency was also documented between the wild and managed populations of Escontria chiotilla (Cactaceae) and Myrtillocactus schenckii (Cactaceae) (Brenda et al., 2006; Ortíz et al., 2010). The density of flowers was significantly higher in the managed population than in the wild population. This demonstrated that A. fulvitarsis preferred to visit the areas with greater flower resource availability.

Phenological results indicated that the anthesis of $Z$. xanthoxylum was different between the wild and managed populations. Single flowering period was two to three days in the wild population while four days in the managed population under natural condition. This difference suggested that both of the vegetation clearance and solar radiation influenced the period of flowering. Similar pattern of phenological variation between the wild and managed populations of Stenocereus quevedonis was documented previously, and the solar radiation on the plants was identified as the dominate factor (Rodríguez-Oseguera et al., 2013).

Pollen limitation also is thought to be an inadequate supply of pollen. Aside from pollen availability, soil nutrient resources, light, temperature and water can also affect plant reproduction, especially for xeroph- 
ilous plants (Haig and Westoby, 1988). Researchers have attempted to identify factors responsible for pollen quantity and quality. Understanding the causes of pollen limitation will improve the prediction of its consequences for plants in different habitats. Previous researches suggested that selection should drive floral traits (e.g. pollen viability and flowering time) to an equilibrium, in which the ability to mature fruit is equally constrained by pollen availability and the availability of other resources (Brenda et al., 2006; Blancas et al., 2009). The frequency of pollen limitation has been suggested to stem from changes in the environment, such as habitat fragmentation (Aizen and Feinsinger, 1994).

Pollen limitation was widely observed in different habitats (Aizen et al., 2002). Our study indicated that both the wild and managed populations of $Z$. xanthoxylum were pollen-limited since significant differences were found between the PA and $\mathrm{C}$ treatments across patches. Most reviews on pollen limitation have found that self-incompatible plants were more prone to being pollen-limited than self-compatible ones, because the latter can mitigate the effects of pollinator scarcity by autogamy (e.g. Galen and Newport, 1988; Larson and Barrett, 2000; Hill et al., 2008). However, the present research modified the study method of pollen limitation and avoided the confounded effects of reallocate resources, which demonstrated that self-compatible plant was pollen-limited in the arid region.

In this study, pollen-supplementation experiments have not been very informative because plants can reallocate resources. To avoid the confounded effects, we used the control from manipulated plants and the procedural control from non-manipulated ones. Then, we found that procedural control had lower reproductive output than the control, suggesting that pollen added to some flowers did not divert resources from the accompanying flowers (Wesselingh, 2007; Gómez et al., 2010).

Recent studies found that pollen limitation is related to the quality and quantity of pollinators (Knight et al., 2005, 2006). Pollinator abundance is a primary factor driving pollen limitation in many plant species (Cosacov et al., 2008). We found a negative relationship across populations between pollinator visitation frequency and $\mathrm{PL}_{C}$ index of $Z$. xanthoxylum. This re- lationship suggested that increased pollinator visitation frequency may decrease the intensity of pollen limitation for seed set between the wild and managed populations.

This study showed that Z. xanthoxylum were self-compatible, yet it produced a small amount of seeds in the absence of pollinators. The pollination treatment demonstrated that $Z$. xanthoxylum was mostly dependent on pollinators for seed set. Self-pollination also played an important assistant role in the breeding system when conditions for out-crossing were unfavorable (Jarne and Charlesworth, 1976). Thus, Z. xanthoxylum displayed a highly adaptive pollination system.

Results from the control treatment revealed that out-crossing is the more effective breeding system in terms of seed set. The high level of out-crossing is likely attributed to the dichogamy. Dichogamy greatly enhances out-crossing and reduces self-pollination, but still carries the limitation of relying on pollinator services (Harder et al., 2000). In addition, the floral morphological traits observed favored pollinators to touch stigmas before anthering, thus favoring out-crossing. This study found that the seed set of self-pollination was higher in the managed population than in the wild population. The relatively higher success of self-pollination in the managed population was an advantage in the production of fruits and seeds even in the period of scarcity of pollinators, and self-pollination probably was a way for plants to produce more fruits and seeds for reproduction by artificial manipulation. A similar situation has been reported for Myrtillocactus schenckii (Cactaceae) in the study of Ortíz et al. (2010), which pointed out that the managed population produced significantly more fruits and seeds per branch than the wild population. The coexistence of individual plants with different fruits and seed sets in the same area suggested that environmental condition was not the only determinant of plant reproductive success (Blancas et al., 2009). Indeed, the role of management or environmental factor in plant reproductive success is still unanswered. This study contributed, in a sense, to a better understanding of the delicate balance of factors regulating pollination success of plants.

In addition, pollination system is an important source 
of information for designing sustainable strategies of plant resources use. Therefore, documenting pollination change in the wild and managed populations and the consequences of such a change is a greater contribution to designing conservation and sustainable use strategies at population levels.

\section{Conclusions}

Z. xanthoxylum is an ecologically important species and widely distributed in arid regions of Northwest China. In this study, the pollination traits of Z. xanthoxylum in the wild and managed populations were compared. We found that the flowering period and flowering peak in the managed $Z$. xanthoxylum population were significantly higher than those in the wild population. The reason is that all the other plant species except for Z. xanthoxylum were cleared in the manage population, and thus $Z$. xanthoxylum could absorb more solar radiation to growth. In addition, the management of vegetation clearance (e.g. managed population) in our study may contribute to explain the differences in the processes of pollen limitation between the two populations.

Pollinators were dominant factors for the development of Z. xanthoxylum and A. fulvitarsis was the most frequent and effective visitor to the flowers. Differences in flower-visitor frequency as well as plant pollination success could be associated with the higher density of flower resources in the managed population and related to the behavior of visitors.

Out-crossing was dominant in the breeding system and self-pollination just played an assistant role to assure the reproduction of $Z$. xanthoxylum. The balance between the artificial management and pollination success is crucial to analyze the pollination process and manipulation of $Z$. xanthoxylum for sustainable use of this species.

\section{Acknowledgements}

This research was funded by the National Science and Technology Support Program (2011BAC07B02) and the National Natural Science Foundation of China (41071185). We thank Naiman Desertification Research Station and Urat Desert-grassland Research Station, Cold and Arid Regions Environmental and Engineering Research Institute, Chinese Academy of Sciences for all the help and support during this study.

\section{References}

Aizen M A, Feinsinger P. 1994. Forest fragmentation, pollination, and plant reproduction in a chaco dry forest, Argentina. Ecology, 75: 330-351.

Aizen M A, Ashworth L, Galetto L. 2002. Reproductive success in fragmented habitats: Do compatibility systems and pollination specialization matter? Journal of Vegetation Science, 13: 885-892

Aizen M A, Harder L D. 2007. Expanding the limits of the pollen-limitation concept: effects of pollen quantity and quality. Ecology, 88: 271-281.

Arias-Cóyotl E, Stoner K E, Casas A. 2006. Effectiveness of bats as pollinators of Stenocereus stellatus (Cactaceae) in wild, managed in situ, and cultivated population in La Mixteca Baja, Central Mexico. American Journal of Botany, 93: 1675-1683.

Ashman T L, Knight T M, Steets J A, et al. 2004. Pollen limitation of plant reproduction: ecological and evolutionary causes and consequences. Ecology, 85: 2408-2421.

Ashman T L, Morgan M T. 2004. Explaining phenotypic selection on plant attractive characters: male function, gender balance or ecological context? Proceedings of the Royal Society: Biological Sciences, 271: 553-559.

Beattie A J. 1971. Technique for study of insect-borne pollen. Pan-Pacific Entomologist, 47: 82.

Blancas J, Casas A, Lira R, et al. 2009. Traditional management and morphological patterns of Myrtillocactus schenkii (Cactaceae) in the Tehuacán Valley, central Mexico. Economic Botany, 63: 375-387.

Bond W J. 1994. Do mutualisms matter: assessing the impact of pollinator and disperser disruption on plant extinction. Philosophical Transactions of the Royal Society: Biological Sciences, 344: 83-90.

Brenda O V, Alejandro C, Alfonso V B. 2006. Reproductive biology in wild and silvicultural managed populations of Escontria chiotilla (Cactaceae) in the Tehuacán Valley, Central Mexico. Genetic Resources and Crop Evolution, 53: 277-287.

Burd M. 1994. Bateman's principle and plant reproduction: the role of pollen limitation in fruit and seed set. Botanical Review, 60: 83-139.

Byers D L. 1995. Pollen quantity and quality as explanations for low seed set in small populations exemplified by Eupatorium (Asteraceae). American Journal of Botany, 82: 1000-1006.

Camargo E, Rodrigues L C, Araujo A C. 2011. Pollination biology and reproduction of Seemannia sylvatica (Kunth) Hanstein (Gesneriaceae) in the Serra da Bodoquena National Park, Mato Grosso do Sul. Biota Neotropica, 4: 125-130.

Casas A, Otero-Arnaiz A, Pérez-Negrón E, et al. 2007. In situ management and domestication of plants in Mesoamerica. Annals of Botany, 100: 1101-1115.

Casper B B, Niesenbaum R A. 1993. Pollen versus resource limitation of seed production: a reconsideration. Current Science, 65: 210-214.

Chen M, Liu L L, Zhang L, et al. 2012. Pollination ecological studies of Tamarix chinensis in the middle reaches of Heihe River and Yantai seashore. Chinese Bulletin of Botany, 47: 264-270.

Chen M, Zhao X Y. 2014. Comparative pollination biology of Tamarix ramosissima in wild and managed populations. Chinese Journal of Ecology, 33: 3169-3175. (in Chinese)

Chen M L. 2009. Comparative reproductive biology of Primula merril- 
liana Schltr. and P. cicutariifolia Pax. Plant Systematics and Evolution, 278: 23-32.

Cosacov A, Nattero J, Cocucci A A. 2008. Variation of pollinator assemblages and pollen limitation in a locally specialized system: the oil-producing Nierembergia linariifolia (Solanaceae). Annals of Botany, 102: 723-734.

Dafni A. 1992. Pollination Ecology: A Practical Approach. New York: Oxford University Press, 1-57.

Galen C, Newport M E A. 1988. Pollination quality, seed set, and flower traits in Polemonium viscosum: complementary effects of variation in flower scent and size. American Journal of Botany, 75: 900-905.

Gómez J M, Abdelaziz M, Lorite J, et al. 2010. Changes in pollinator fauna cause spatial variation in pollen limitation. Journal of Ecology, 98: 1243-1252.

Harder L, Barrett S, Cole W. 2000. The mating consequences of sexual segregation within inflorescences of flowering plants. Proceedings of the Royal Society: Biological Sciences, 267: 315-320.

Hill L M, Brody A K, Tedesco C L. 2008. Mating strategies and pollen limitation in a globally threatened perennial Polemonium vanbruntiae. Acta Oecologica-International Journal of Ecology, 33: 314-323.

Hu X K, Li Y, Li D L, et al. 2012. Spatial distribution pattern of desert plants Zygophyllum xanthoxylum. Journal of Southwest Forestry University, 32(4): 61-65. (in Chinese)

Janzen D H. 1977. A note on optimal mate selection in plants. American Naturalist, 111: 365-371.

Jarne P, Charlesworth D. 1976. The evolution of the selfing rate in functionally hermaphrodite plants and animals. Annual Review of Ecology and Systematics, 24: 441-466.

Kawakita A. 2010. Evolution of obligate pollination mutualism in the tribe Phyllantheae (Phyllanthaceae). Plant Species Biology, 25: 3-19.

Kearns C A, Inouye D W, Waser N M. 1998. Endangered mutualisms: the conservation of plant-pollinator interactions. Annual Review of Ecology and Systematics, 29: 83-112.

Kevan P G, Clark E A, Thomas V G. 1990. Insect pollination and sustainable agriculture. American Journal of Alternative Agriculture, 5: 12-22.

Knight T M, Steets J A, Vamosi J C, et al. 2005. Pollen limitation of plant reproduction: ecological and evolutionary causes and consequences. Annual Review of Ecology Evolution and Systematics, 36: 467-497.

Knight T M, Steet J A, Ashman T L. 2006. A quantitative synthesis of pollen supplementation experiments highlights the contribution of resource reallocation to estimates of pollen limitation. American Journal of Botany, 93: 271-277.

Kuchlein J H, Ellis W N. 1997. Climate-induced changes in the microlepidoptera fauna of the Netherlands and the implications for nature conservation. Journal of Insect Conservation, 1: 73-80.

Kudo G. 1993. Relationships between flowering time and fruit set of the entomophilous alpine shrub, Rhododendron aureum (Ericaceae), inhabiting snow patches. American Journal of Botany, 80: 1300-1304.

Larson B M H, Barrett S C H. 2000. A comparative analysis of pollen limitation in flowering plants. Biological Journal of the Linnean Society, 69: 503-520.

Li X W, Teng H K. 1990. The Flora of China. Beijing: Science Press, 140-142. (in Chinese)

Li Y, Li D L, Zhu G Q, et al. 2013. Study on the niche of Zygophyllum xanthoxylum community in Minqin desert area. Journal of Arid Land Resources and Environment, 27(1): 120-125. (in Chinese)

Liu Y X. 1987. Chinese Desert Flora. Beijing: Science Press, 318-320. (in
Chinese)

Lloyd D G. 1980. Demographic factors and mating patterns in angiosperms. In: Solbrig O T. Demography and Evolution in Plant Populations. Berkeley: University of California Press, 67-88.

Ma Q, Yue L J, Zhang J L, et al. 2012. Sodium chloride improves photosynthesis and water status in the succulent xerophyte Zygophyllum xanthoxylum. Tree Physiology, 32: 4-13.

McCarty J P. 2001. Ecological consequences of recent climate change. Conservation Biology, 15: 320-331.

Michael A W, Margaret T E, Robert S B. 2003. Conservation impact of climatic variability on pollination of the federally endangered plant, Clematis socialis (Ranunculaceae). Southeastern Naturalist, 2: 11-24.

Ortíz F E, Stoner K, Pérez-Negrón E, et al. 2010. Pollination biology of Myrtillocactus schenckii (Cactaceae) in wild and managed populations of the Tehuacán Valley, México. Journal of Arid Environments, 74: 897-904.

Rathcke B. 1983. Competition and facilitation among plants for pollinators. In: Real LA. Pollination Biology. New York: Academic Press, 305-329.

Revel N, Alvarez N, Gibernau M, et al. 2012. Investigating the relationship between pollination strategies and the size-advantage model in zoophilous plants using the reproductive biology of Arum cylindraceum and other European Arum species as case studies. Arthropod-Plant Interactions, 6: 35-44.

Rodríguez-Oseguera1 A G, Casas A, Herrerías-Diego Y, et al. 2013. Effect of habitat disturbance on pollination biology of the columnar cactus Stenocereus quevedonis at landscape-level in central Mexico. Plant Biology, 15: 573-582.

Saetersdal M, Birks H J B. 1997. A comparative ecological study of Norwegian mountain plants in relation to possible future climate change. Journal of Biogeography, 24: 127-152.

Spira T P, Snow A A, Whigham D F, et al. 1992. Flower visitation, pollen deposition, and pollen-tube competition in Hibiscus moscheutos (Malvaceae). American Journal of Botany, 79: 428-433.

Spira T P. 2001. Plant-pollinator interactions: A threatened mutualism with implications for the ecology and management of rare plants. Natural Areas Journal, 21: 78-88.

Wesselingh R A. 2007. Pollen limitation meets resource allocation: towards a comprehensive methodology. New Phytologist, 174: 26-37.

Wiemer A P, Sérsic A N, Marino S, et al. 2012. Functional morphology and wasp pollination of two South American asclepiads (Asclepiadoideae-Apocynaceae). Annals of Botany, 109: 77-93.

Wilson P, Thomson J D, Stanton M L. 1994. Beyond floral Batemania: gender biases in selection for pollination success. American Naturalist, 143: 283-296.

Wu G Q, Wang Q, Bao A K, et al. 2011a. Amiloride reduces sodium transport and accumulation in the succulent xerophyte Zygophyllum xanthoxylum under salt conditions. Biological Trace Element Ressearch, 139: 356-367.

Wu G Q, Xi J J, Wang Q, et al. 2011b. The ZxNHX gene encoding tonoplast $\mathrm{Na}^{+} / \mathrm{H}^{+}$antiporter from the xerophyte Zygophyllum xanthoxylum plays important roles in response to salt and drought. Journal of Plant Physiology, 168: 758-767.

Yue L J, Li S X, Ma Q, et al. 2012. $\mathrm{NaCl}$ stimulates growth and alleviates water stress in the xerophyte Zygophyllum xanthoxylum. Journal of Arid Environments, 87: 153-160.

Zapata T R, Arroyo M T K. 1978. Plant reproductive ecology of a secondary deciduous tropical forest in Venezuela. Biotropica, 10: 221-230. 